\title{
(2) OPEN ACCESS \\ Healthcare system impacts of the 2017 Manchester Arena bombing: evidence from a national trauma registry patient case series and hospital performance data
}

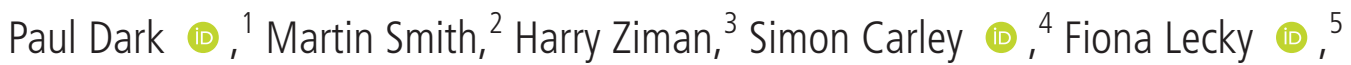 \\ Manchester Academic Health Science Centre (MAHSC) Collaborators
}

Handling editor Edward Carlton

- Additional supplemental material is published online only. To view, please visit the journal online (http://dx.doi. org/10.1136/emermed-2019208575).

${ }^{1}$ Humanitarian and Conflict Response Institute, University of Manchester, Manchester, UK ${ }^{2}$ Emergency Department, Salford Royal Hospitals NHS Trust, Salford, UK

${ }^{3}$ PHS Consulting Ltd, Tarvin, UK ${ }^{4}$ Manchester University NHS Foundation Trust, Manchester, UK

${ }^{5}$ Centre for Urgent and Emergency Care Research, The University of Sheffield, Sheffield, UK

\section{Correspondence to}

Professor Paul Dark,

Humanitarian and Conflict

Response Institute, University of Manchester, Manchester M13 9PL, UK;

paul.m.dark@manchester.ac.uk

Received 11 March 2019

Revised 4 April 2021

Accepted 8 April 2021

D) Check for updates

(C) Author(s) (or their employer(s)) 2021. Re-use permitted under CC BY-NC. No commercial re-use. See rights and permissions. Published by BMJ.

To cite: Dark $P$,

Smith M, Ziman $\mathrm{H}$, et al.

Emerg Med J Epub ahead

of print: [please include Day

Month Year]. doi:10.1136/

emermed-2019-208575

\section{ABSTRACT}

Introduction In response to detonation of an improvised explosive device at the Manchester Arena on 22 May 2017, we aimed to use detailed information about injured patients flowing through hospital healthcare to objectively evaluate the preplanned responses of a regional trauma care system and to show how routinely collected hospital performance data can be used to assess impact on regional healthcare.

Methods Data about injury severity, management and outcome for patients presenting to hospitals were collated using England's major trauma registry for 30 days following hospital attendance. System-wide data about hospital performance were collated by National Health Service England's North West Utilisation Management Unit and presented as Shewhart charts from 15 April 2017 to 25 June 2017.

Results Detailed information was obtained on 153 patients (109 adults and 44 children) who attended hospital emergency departments after the incident. Within 6 hours, a network of 11 regional trauma care hospitals received a total of 138 patients (90\%). For the whole patient cohort, median Injury Severity Score (ISS) was 1 (IQR 1-10) and median New ISS (NISS) was 2 (IQR 1-14). For the 75 patients (49\%) attending a major trauma centre, median ISS was 7.5 (IQR 1-14) and NISS was 10 (IQR 3-22). Limb and torso body regions predominated when injuries were classified as major life threatening (Abbreviated Injury Scale>3). Ninety-three patients $(61 \%)$ required hospital admission following emergency department management, with 21 (14\%) requiring emergency damage control surgery and 24 $(16 \%)$ requiring critical care. Three fatalities occurred during early resuscitative treatment and 150 (98\%) survived to day 30 . The increased system-wide hospital admissions and care activity was linked to increases in regional hospital care capacity through cancellations of elective surgery and increased community care. Consequently, there were sustained system-wide hospital service improvements over the following weeks.

Conclusions The systematic collation of injured patient and healthcare system data has provided an objective evaluation of a regional major incident plan and provided insight into healthcare system resilience. Hospital patient care data indicated that a prerehearsed patient dispersal plan at incident scene was implemented effectively.

\section{Key messages}

What is already known on this subject

- There is an acknowledged inadequate evidence base to assess healthcare responses to civilian terrorist attacks and to inform health systems planning.

What this study adds

- Systematic collation of both individual patient hospital data (through deployment of a national trauma register) and hospital performance data has allowed evaluation of a civilian trauma care system's planned responses to a major terrorist incident and healthcare system resilience.

- Collection, archiving and use of patient and healthcare data in an agreed, standardised way can facilitate improvements in the evidence base and learning from a mass casualty civilian terrorist attack.

\section{INTRODUCTION}

Major public health concerns regarding healthcare system preparedness for civilian terrorist attacks have been raised regularly despite well publicised guidance on the preparation and response to major incidents. ${ }^{12}$ Systematic reviews of data reported from patient case series ${ }^{3}$ or reviews of mass casualty management strategies ${ }^{4}$ all help inform on learning and health systems planning for terrorist attack in civilian settings. ${ }^{5}$ However, low-quality case reporting and anecdotal expert opinion contribute to an acknowledged limited evidence base of relevant patient and health services data from real major incidents. ${ }^{3-6}$

The preparation of emergency response plans for major trauma incidents requires systems level information that can be used to anticipate the demands placed on a healthcare system. ${ }^{6}$ Such data can be obtained as part of simulated exercises ${ }^{78}$ but are ideally obtained from healthcare system responses to major incidents. The systematic collection, archiving and publication of data of an internationally agreed nature would provide a body of information to planning processes and support capacity assessment, but this is not routinely done. 
This paper reports detailed injury and care data systematically by utilising an established national trauma registry and delineates patient flow through a civilian healthcare system following a major terrorism incident. These patient-level data provide an opportunity to objectively evaluate a trauma care system's planned healthcare responses. We also show how routinely collected system-wide healthcare performance data can be used to assess the consequent impact on regional healthcare provision.

\section{METHODS}

\section{Incident description}

Data presented in this paper arise from the responses of an integrated acute healthcare system to events at the Manchester Arena, UK, on 22 May 2017. A shrapnel-laden improvised explosive device (IED) was detonated at 22:31 in one of the Arena's foyers. Attendees were streaming out of the 21000 -capacity auditorium, the largest indoor arena in the UK, following a concert by the American singer Ariana Grande.

\section{Healthcare system setting}

The National Health Service (NHS) is the publicly funded national healthcare system in the UK. It provides healthcare to every resident, with most services-including community and hospital emergency care-free at the point of delivery. NHS England operates the major trauma service in Manchester as a single service system, the Greater Manchester Major Trauma Services Network (GMMTSN), which serves a city of circa 3 million people 180 miles north-west of London.

The GMMTSN was launched in 2012 based on a realisation that no single hospital in Greater Manchester had the full spectrum of clinical services to act as a single major trauma centre (MTC). The GMMTSN engage healthcare providers throughout the city to provide a planned response to trauma with defined patient and staff pathways. It includes a single, integrated prehospital emergency medical service (EMS) - the North West Ambulance Service (NWAS). The structure of the GMMTSN is unusual in the UK (online supplemental figure S1) where it is more common for a single NHS organisation to provide a MTC service to a regional network of trauma units and local emergency hospitals, although paediatric major trauma services are often provided separately from adult services.

\section{Major incident plans}

GMMTSN's plans for major trauma events were revised following the 2015 multisite terrorist attacks in Paris and other incidents that year. ${ }^{9-14}$ The planned and rehearsed scheme for system-wide patient dispersal (the Patient Dispersal Framework) in the event of a major incident is detailed in online supplemental figure S2. The plan did not include provision for collation of patient or healthcare system data.

\section{Data collection and sources}

Prehospital

Information about incident timelines, prehospital responses, patient triage priority categories at scene and ambulance transport from incident scene was collated by the NWAS and formed part of a report to the Kerslake public review into the preparedness and emergency responses to the Manchester Arena bombing. 15

\section{Emergency department and acute hospital}

The Trauma Audit and Research Network (TARN) registry, established over 25 years ago, collects prospective, observational data from hospitalised major trauma patients in all trauma care networks across England. ${ }^{16}$ TARN provides NHS England with confidential information about trauma systems performance. When data are available to emergency departments, the TARN registry also includes patient level prehospital data for those subsequently receiving hospital care but does not include patients confirmed dead at the injury scene.

As part of GMMTSN's emergency responses to the incident, and in response to NHS England's requests for regular incident updates, the TARN registry was deployed to collate and archive anonymised healthcare data for all incident patients attending emergency departments (including any outside of Greater Manchester) and subsequent hospital care to 30 days irrespective of injury severity or hospital admission status. Data included physiological status at hospital arrival and anatomical injuries to derive Injury Severity Scores (ISS) (online supplemental material methods S1). In addition, data were captured on management, hospital healthcare utilisation, patient disposition and all-cause mortality to 30 days. All research for publication from the TARN database is overseen by the TARN Board which is a multidisciplinary group including patient and public representatives.

\section{Greater Manchester acute healthcare system}

Routinely collected system-wide time series data about the provision of acute hospital healthcare were obtained from the North West Utilisation Management Unit (https://healthinnova tionmanchester.com/our-work/utilisation-management/). Data were collated about hospital emergency attendances, emergency

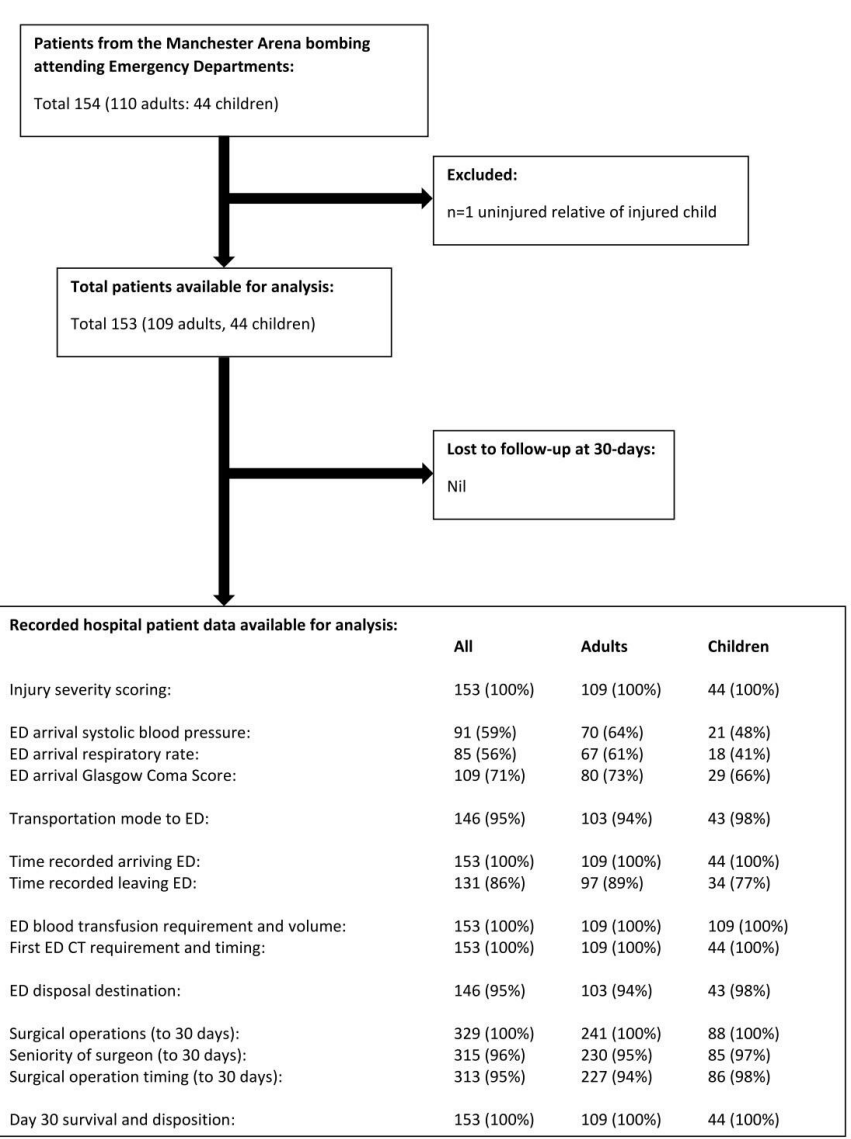

Figure 1 Flow diagram for TARN registered patient data. ED, emergency department; TARN, Trauma Audit and Research Network. 
Box 1 Letter to survivors, hospital patients, relatives of hospital patients and members of bereaved families following the

Manchester Arena bombing

We are contacting you because you were a survivor, hospital patient, or a relative of a hospital patient, or a member of the bereaved families following the Manchester Arena bombing in May 2017.

We would like to let you know about a medical research report that we have written about the hospital responses to the Manchester Arena bombing incident. Our report is based on anonymised information (ie, patients cannot be identified) that is routinely collected for the National Health Service (NHS) by the Trauma Audit and Research Network (TARN). Working with TARN and the NHS, we have been able to evaluate Manchester hospitals planned emergency responses to the incident, identifying good practice and improvements for the future.

Major incidents continue to occur around the world. In the past, we have learnt valuable lessons from colleagues in the UK and abroad. It is, therefore, very important for us to share our learning from Manchester with the wider international healthcare communities. Publishing a scientific article, in a peer-reviewed international medical journal, is the established format for achieving this effectively.

Our completed report has now been reviewed confidentially by the British Medical Journal Publishing Group's Emergency Medicine Journal, including input from independent international experts in the field, and a final version has been accepted for publication later in 2020.

There was an agreement that before this article was published, we would inform you of its content and, more importantly, its significant value in assessing and improving major incident plans for the future. Therefore, we are contacting you-following help from Manchester City Council and Greater Manchester Police (GMP)— to seek your support if you were hospitalised to proceed with publication.

Our report publication will be read by doctors and other healthcare professionals but will also be seen by many others including journalists and the public. Therefore, our report may be the subject of press coverage. You have our commitment that we will work with Manchester City Council and GMP to ensure that you are fully informed about any planned press releases in advance.

We thank you for your time considering our request for support to publish our report. A copy of our scientific report can be provided to you if you would like to read it. We have decided not to send this directly to you as already mentioned it is very technical with a specific audience in mind. We are concerned that any report about the Arena bombing may cause some distress and upset.

We ask that you reply to us by email before 15 August 2020 so that the report authors and the Emergency Medicine Journal editors can review your feedback and gauge the level of support prior to a final decision to publish.

Yours faithfully,

Professor Paul Dark, The University of Manchester

Dr Martin Smith, Lead of Greater Manchester NHS Major Trauma Services

$15^{\text {th }}$ July 2020.

\section{Commentary from Respondent 27}

I have read the Emergency Medical Journal report and noted things that I am NOT happy to read, as I truly believe that in parts it does not accurately reflect what I experienced on that night in the aftermath. I also believe it will mislead anyone reading it, so I do not support its release to the public. I have given and written several witness statements for the police investigations and the Kerslake Report, none of which represent my experiences.

I accept that investigations and reports will always be very sensitive for those seriously affected by this tragic event and who will live with it for the rest of their lives. However, I cannot understand why those involved in finding out the details of what happened that night would continually cause me (and no doubt all the others affected) more stress, frustration and indeed psychological pain and suffering having to read facts that I do not believe are correct.

I will just highlight some important facts that from my perspective don't match in this Emergency Medicine Journal report and I request them to be duly noted:

1. Numbers of casualties, timings for causality evacuation and medical help arriving into the foyer (City room), discrepancies between various governing bodies and reports, who is correct?

2. During the aftermath in the foyer (City room, where the bomb was detonated) My sister and I did not receive any 'top to toe' assessment from anyone and it was quite some time before I saw any 'official' medical person enter the foyer (City room). I do not agree that all casualties including myself were removed from scene (foyer-City room) within the 'golden hour'.

3. When I was finally removed from the foyer (City room) and taken to the train station holding area (War Memorial entrance).

Paramedics made several attempts to assess me but each time they were stopped and taken away to assist with other casualties. From my perspective and personal experience assessments were chaotic and not well organised or co-ordinated.

A paramedic finally refused to leave me expressing his findings of my injuries and I was immediately upgraded in priority to go to hospital in the next available ambulance to arrive.

4. In the chaos, I witnessed this ambulance crew being pressured to move me and get me to hospital even after they had expressed concerns that they didn't have directions which hospital to go to and someone else was using their vehicle. They were then shouted at to use another vehicle and get me gone! This resulted in the crew having no keys to access the lockers that contained invaluable pain relief for me. I was moved into the ambulance where there was a further delay waiting for directions where to go. I was driven to a hospital some distance away. I did not receive any pain relief at any point that night. (Until I arrived at hospital in the early hours next morning).

I also witnessed difficulties the ambulance crew had reaching the hospital due to the sat navigation not working which resulted in them having to use a mobile phone to get directions. Difficulties continued as security roadblocks kept turning the driver back and forth causing more delay. 


\section{Box 1 Continued}

5. On arriving to hospital I saw the time on the wall clock in the emergency department. The same time was logged on my medical records by the trauma team, which confirms to me I was correct. This has assisted me to work out the time frame against sequence of my movements after the explosion and questions I have raised about timings discrepancies in reports.

6. The patient identification card and wristband issued whilst I was in the foyer (City room) identifying important timing, injuries and information about me, was removed by a paramedic while I was in the train station (War Memorial entrance) it was not replaced in the chaos so it did not accompany me to the hospital. I was told by the GMP weeks after the event that many cards were retrieved that night, however, when I asked could I have mine back I was told they had all been destroyed! Surely this information is crucial to understand what happened at the scene, therefore I cannot believe or accept that such important evidence was so quickly disposed off. Why?

I sat amongst the dead, dying and those fighting for life, I observed the pain and suffering and endured my own. I need to hear the truth to be able to move forward and I have to be there for those who didn't make it, they do not have a say in this, so I must speak up for them and for my own mental wellbeing, I cannot rest until the truth is told and evidence is shown to me around what actually happened from all departments responsible for finding out the truth!

Respondent 27, 14 December 2020.

department care completion, hospital admissions, cancelled elective surgery, hospital bed utilisation, patient discharges to the community and their delays.

\section{Data presentation and analyses}

TARN patient case series

The patient case series is reported using Strengthening the Reporting of Observational Studies in Epidemiology criteria and figure 1 shows the study flow chart. No data imputation methods were used for missing data. Patient-level data are reported as medians and interquartile ranges or counts and percentages as appropriate. For these observational data, no formal statistical subgroup analyses were planned in advance. In addition, the incident hospital data were not suitable for case mix based excess survival analysis due to the small number of deaths after reaching hospital alive $(n=3)$.

\section{Routine hospital performance data}

Whole system acute hospital performance data for Greater Manchester are displayed as Shewhart (process behaviour) charts. ${ }^{17}$ Moving average data were modelled (after Koutras et $a l^{17}$ ) by the NHS North West Utilisation Management Unit for 3 months around the incident data, with lower confidence limits (lcl) and upper $\mathrm{cl}(\mathrm{ucl})$ indicating the $99.7 \%$ expected data limits. Six consecutive weeks of data from 15 April 2017 to 25 June 2017 were charted, including modelled mean daily values with upper and lower 99.7\% confidence limits, with recorded daily data superimposed. Daily recorded data patterns were identified for interpretation using the following rule set ${ }^{17}$ : (1) Any points approaching or outside the control limits (ucl or lcls); (2) A run of 7 points all above or all below the mean data line and (3) A run of 7 points up or down.

\section{Patient and public involvement}

Patients and the public are represented on the TARN Oversight Board who have reviewed and approved this work as it was designed in response to a major incident. Patients and relatives were approached for support to produce this manuscript and the full reply from a patient is published as part of our manuscript.

\section{Ethical considerations}

TARN has NHS Health Research Authority (Confidential Advisory Group Section 251) ethics approval to conduct research on anonymised patient data. Given the sensitive nature of the data reported in this manuscript, we do not reproduce actual group numbers when the count is less than 5 to protect from risk of patient identification.

The manuscript was reviewed by the Caldicott Guardian for the Greater Manchester Health and Social Care Partnership, Health Innovation Manchester (Greater Manchester's health and social care research partnership) and representatives of Manchester City Council. Survivors, hospital patients, relatives of hospital patients and members of bereaved families were approached by Greater Manchester Police (GMP) on behalf of authors (PMD and MS) to seek support to publish this manuscript (box 1). These 1004 individuals receive regular confidential email communications from GMP about, for example, relevant legal cases and public inquiries related to the Manchester Arena bombing. GMP received 27 email replies, of which 26 were supportive of manuscript publication and with one respondent not supportive (responder 27). Subsequently, responder 27 agreed to write a commentary in their own words to accompany our manuscript (box 1) and is supportive of our approach to publication. On behalf of the authors, GMP distributed a copy of the final manuscript to the 1004 individuals in advance of its publication.

\section{RESULTS}

\section{Information from scene}

The IED detonation in the Manchester Arena occurred at 22:31 hour on 22 May 2017. A major incident was declared at 22:46 which activated a preplanned, rehearsed systems response, including implementation of the Patient Dispersal Framework. 300 health service personnel contributed to coordinating incident responses and/or attending the scene including 60 paramedic ambulances with crews, 8 paramedic rapid response vehicles, 6 advanced paramedic practitioners, 6 doctors and 3 teams trained to operate in hazardous areas. The scene recorded information using a patient-level cruciate card system. 59 patients were transported by NWAS to GMMTSN hospitals. NWAS reported the distribution of recorded triage priority codes at scene for these patients as: P1-requires immediate lifesaving treatment $(n=21) ;$ P2-requires urgent treatment within 6 hours $(n=24)$ and $\mathrm{P} 3$ - can be delayed treatment no time limit $(\mathrm{n}=14)$. Twenty people died at scene, including the person that detonated the IED. By 2:46 hour the following morning, all live patients had been conveyed from the scene. An additional P3 patients $(n=95)$ made their own way to hospitals, self-presenting at an emergency 
Table 1 Major incident patients presenting to emergency departments (ED)

\begin{tabular}{|c|c|c|c|c|c|c|}
\hline & \multicolumn{2}{|l|}{ All patients } & \multicolumn{2}{|c|}{ Adults ( $\geq 16$ years) } & \multicolumn{2}{|c|}{ Children ( $<16$ years) } \\
\hline No $(\%)$ & $153(100 \%)$ & & $109(71 \%)$ & & $44(29 \%)$ & \\
\hline Median (IQR) age in years & $36(15-47)$ & & $45(34-50)$ & & $13(12-14)$ & \\
\hline No $(\%)$ of females & $107(70 \%)$ & & $68(62 \%)$ & & $40(91 \%)$ & \\
\hline No (\%) of all ED patient arrivals and no requiring critical care (CC) & ED & CC & ED & $\mathrm{CC}$ & ED & $\mathrm{CC}$ \\
\hline \multicolumn{7}{|l|}{ GM Major Trauma Care System } \\
\hline MTC-1 & $26(17 \%)$ & $<5(<3 \%)$ & $25(16 \%)$ & $<5(<3 \%)$ & $<5(<3 \% \%)$ & $0(0 \%)$ \\
\hline MTC-2 & $8(5 \%)$ & $5(3 \%)$ & $8(5 \%)$ & $5(3 \%)$ & $0(0 \%)$ & $0(0 \%)$ \\
\hline MTC-3 & $8(5 \%)$ & $5(3 \%)$ & $8(5 \%)$ & $5(3 \%)$ & $0(0 \%)$ & $0(0 \%)$ \\
\hline P-MTC & $26(17 \%)$ & $5(3 \%)$ & $<5(<3 \%)$ & $0(0 \%)$ & $22(14 \%)$ & $5(3 \%)$ \\
\hline TU-1 & $14(9 \%)$ & $0(0 \%)$ & $10(6 \%)$ & $0(0 \%)$ & $<5(<3 \%)$ & $0(0 \%)$ \\
\hline TU-2 & $11(7 \%)$ & $<5(<3 \%)$ & $10(6 \%)$ & $<5(<3 \% \%)$ & $<5(<3 \%)$ & $0(0 \%)$ \\
\hline TU-3 & $0(0 \%)$ & $0(0 \%)$ & $0(0 \%)$ & $0(0 \%)$ & $0(0 \%)$ & $0(0 \%)$ \\
\hline LEH-1 & $17(11 \%)$ & $<5(<3 \%)$ & $12(8 \%)$ & $<5(<3 \%)$ & $5(3 \%)$ & $0(0 \%)$ \\
\hline LEH-2 & $17(11 \%)$ & $<5(<3 \%)$ & $14(9 \%)$ & $<5(<3 \%)$ & $<5(<3 \%)$ & $0(0 \%)$ \\
\hline LEH-3 & $8(5 \%)$ & $0(0 \%)$ & $5(3 \%)$ & $0(0 \%)$ & $<5(<3 \%)$ & $0(0 \%)$ \\
\hline LEH-4 & $<5(<3 \%)$ & $0(0 \%)$ & $<5(<3 \%)$ & $0(0 \%)$ & $<5(<3 \%)$ & $0(0 \%)$ \\
\hline \multicolumn{7}{|l|}{ Outside GM Major Trauma Care System } \\
\hline MTC & $6(4 \%)$ & $0(0 \%)$ & $<5(<3 \%)$ & $0(0 \%)$ & $<5(<3 \%)$ & $0(0 \%)$ \\
\hline Non-MTC & $9(6 \%)$ & $0(0 \%)$ & $7(5 \%)$ & $0(0 \%)$ & $<5(<3 \%)$ & $0(0 \%)$ \\
\hline Total & $153(100 \%)$ & $\begin{array}{l}24 \\
(16 \%)\end{array}$ & $\begin{array}{l}109 \\
(71 \%)\end{array}$ & $\begin{array}{l}19 \\
(12 \%)\end{array}$ & $\begin{array}{l}44 \\
(29 \%)\end{array}$ & $\begin{array}{l}5 \\
(3 \%)\end{array}$ \\
\hline Mode of presentation to ED & \multicolumn{2}{|l|}{$\begin{array}{l}\text { All patients } \\
(\mathrm{n}=153)\end{array}$} & \multicolumn{2}{|c|}{$\begin{array}{l}\text { Adults }(\geq 16 \text { years }) \\
(n=109)\end{array}$} & \multicolumn{2}{|c|}{$\begin{array}{l}\text { Children ( }<16 \text { years }) \\
(\mathrm{n}=44)\end{array}$} \\
\hline No (\%) by ambulance service & \multicolumn{2}{|l|}{$59(39 \%)$} & \multicolumn{2}{|l|}{$43(39 \%)$} & \multicolumn{2}{|l|}{$16(36 \%)$} \\
\hline No (\%) by car & \multicolumn{2}{|l|}{$57(37 \%)$} & \multicolumn{2}{|l|}{$38(35 \%)$} & \multicolumn{2}{|l|}{$19(43 \%)$} \\
\hline No (\%) walked & \multicolumn{2}{|l|}{$<5(<3 \%)$} & \multicolumn{2}{|l|}{$<5(<4 \%)$} & \multicolumn{2}{|l|}{$0(0 \%)$} \\
\hline No (\%) not recorded & \multicolumn{2}{|l|}{$33(22 \%)$} & \multicolumn{2}{|l|}{$24(22 \%)$} & \multicolumn{2}{|l|}{$9(20 \%)$} \\
\hline Median (IQR) Injury Severity overall and at MTCs & $\begin{array}{l}\text { Overall } \\
(\mathrm{n}=153)\end{array}$ & $\begin{array}{l}\text { MTC } \\
(n=74)\end{array}$ & $\begin{array}{l}\text { Overall } \\
(\mathrm{n}=109)\end{array}$ & $\begin{array}{l}\text { MTC } \\
(n=49)\end{array}$ & $\begin{array}{l}\text { Overall } \\
(\mathrm{n}=44)\end{array}$ & $\begin{array}{l}\text { MTC } \\
(n=25)\end{array}$ \\
\hline Median (IQR) ISS & $1(1-10)$ & $7.5(1-14)$ & $1(1-10)$ & $6(2-14)$ & $2(1-9)$ & $5(1-14)$ \\
\hline Median (IQR) NISS & $2(1-14)$ & $10(3-22)$ & $2(1-14)$ & $9(3-22)$ & $2(1-14)$ & $10(3-22)$ \\
\hline No (\%) ISS 1-8 & $104(68 \%)$ & $37(50 \%)$ & $71(65 \%)$ & $23(47 \%)$ & $33(75 \%)$ & $14(56 \%)$ \\
\hline No (\%) ISS 9-15 & $30(20 \%)$ & $19(26 \%)$ & $26(24 \%)$ & $15(32 \%)$ & $<5(<11 \%)$ & $<5(<25 \%)$ \\
\hline No $(\%)$ ISS $>15$ & $19(12 \%)$ & $18(24 \%)$ & $12(11.0 \%)$ & $11(22.0 \%)$ & $7(16 \%)$ & $7(28 \%)$ \\
\hline No (\%) NISS $1-8$ & $98(64 \%)$ & $32(43 \%)$ & $68(62 \%)$ & $2143 \%)$ & $30(68 \%)$ & $11(44 \%)$ \\
\hline No (\%) NISS 9-15 & $18(12 \%)$ & $12(16 \%)$ & $14(13 \%)$ & $8(16 \%)$ & $<5(<11 \%)$ & $4(16 \%)$ \\
\hline No (\%) NISS >15 & $37(24 \%)$ & $30(40 \%)$ & $27(25 \%)$ & 20 (41\%) & $10(23 \%)$ & $10(40 \%)$ \\
\hline $\begin{array}{l}\text { No (\%) of patients with major injuries by body region (AIS } \geq 3 \text { ) overall and } \\
\text { at MTCs }\end{array}$ & $\begin{array}{l}\text { Overall } \\
(n=153)\end{array}$ & $\begin{array}{l}\text { MTCs } \\
(n=74)\end{array}$ & $\begin{array}{l}\text { Overall } \\
(n=109)\end{array}$ & $\begin{array}{l}\text { MTCs } \\
(\mathrm{n}=49)\end{array}$ & $\begin{array}{l}\text { Overall } \\
(\mathrm{n}=44)\end{array}$ & $\begin{array}{l}\text { MTCs } \\
(n=25)\end{array}$ \\
\hline No (\%)-head & $6(4 \%)$ & $6(8 \%)$ & $<5(<5 \%)$ & $<5(<10 \%)$ & $<5(<11 \%)$ & $<5(<20 \%)$ \\
\hline No (\%)-face & $<5(<3 \%)$ & $<5(<7 \%)$ & $<5(<5 \%)$ & $<5(<10 \%)$ & $0(0 \%)$ & $0(0 \%)$ \\
\hline No (\%)-chest & $12(8 \%)$ & $10(13 \%)$ & $7(6 \%)$ & $5(10 \%)$ & $5(11 \%)$ & $5(20 \%)$ \\
\hline No (\%)—abdomen & $<5(<3 \%)$ & $<5(<7 \%)$ & $<5(<5 \%)$ & $<5(<10 \%)$ & $<5(<11 \%)$ & $<5(<20 \%)$ \\
\hline No (\%)—spine & $<5(<3 \%)$ & $<5(<7 \%)$ & $<5(<5 \%)$ & $<5(<10 \%)$ & $0(0 \%)$ & $0(0 \%)$ \\
\hline No (\%)—pelvis & $<5(<3 \%)$ & $0(0 \%)$ & $<5(<5 \%)$ & $0(0.0 \%)$ & $0(0.0 \%)$ & $0(0.0 \%)$ \\
\hline No $(\%)$-limbs & $32(21 \%)$ & $21(28 \%)$ & $26(24 \%)$ & $15(31 \%)$ & $6(14 \%)$ & $6(24 \%)$ \\
\hline No (\%)-burns & $5(3 \%)$ & $5(7 \%)$ & $<5(<5 \%)$ & $<5(<10 \%)$ & $<5(<11 \%)$ & $<5(<20 \%)$ \\
\hline Time before arrival in ED & $\begin{array}{l}\text { All patients } \\
(\mathrm{n}=153)\end{array}$ & & $\begin{array}{l}\text { Adults }(>16 \\
(\underline{n}=109)\end{array}$ & & $\begin{array}{l}\text { Children }(<16 \\
(n=44)\end{array}$ & years) \\
\hline Median (IQR) minutes & $192(94-287)$ & & $187(92-286$ & & $230(95-285)$ & \\
\hline Patients arriving in ED within 6 hours by ISS & & & & & & \\
\hline No (\%) ISS 1-8 & $78(51 \%)$ & & $53(49 \%)$ & & $25(57 \%)$ & \\
\hline No (\%) ISS 9-15 & $28(18 \%)$ & & $24(22 \%)$ & & $4(9 \%)$ & \\
\hline No (\%) ISS >15 & $18(12 \%)$ & & $11(10 \%)$ & & $7(16 \%)$ & \\
\hline Median (IQR) minutes before ED arrival ISS 1-8 & $108(70-242)$ & & $105(70-194$ & & $128(91-270)$ & \\
\hline Median (IQR) minutes before ED arrival ISS 9-15 & $234(180-255)$ & & $230(180-25$ & & $245(236-25$ & \\
\hline
\end{tabular}




\begin{tabular}{|c|c|c|c|}
\hline & All patients & Adults ( $\geq 16$ years) & Children ( $<16$ years) \\
\hline Median (IQR) minutes before ED arrival ISS $>15$ & $129(101-196)$ & $125(95-184)$ & $178(133-246)$ \\
\hline \multicolumn{4}{|l|}{ Time in ED } \\
\hline Median (IQR) minutes & $151(99-223)$ & $151(109-240)$ & $158(99-205)$ \\
\hline \multicolumn{4}{|l|}{ First ED CT-scan } \\
\hline No (\%) requiring ED CT-scan & $41(27 \%)$ & $35(32 \%)$ & $6(14 \%)$ \\
\hline Median (IQR) minutes to first ED CT-scan & $49(25-82)$ & $49(25-82)$ & $51(47-55)$ \\
\hline \multicolumn{4}{|l|}{ First surgical operation } \\
\hline Median (IQR) minutes to first surgical operation & $558(285-875)$ & $565(285-893)$ & $536(374-786)$ \\
\hline \multicolumn{4}{|l|}{ Blood transfusion from ED arrival in first 24 hours } \\
\hline No (\%) requiring blood transfusion & $13(8 \%)$ & $10(9 \%)$ & $<5(<11 \%)$ \\
\hline Median (IQR) units used for those requiring blood transfusion & $1(1-2)$ & $2(2-4)$ & $1(1-1)$ \\
\hline \multicolumn{4}{|l|}{ ED disposition } \\
\hline Died in ED (mortuary) & $<5(<3 \%)$ & $<5(<5 \%)$ & $<5(<11 \%)$ \\
\hline Operating rooms & $21(14 \%)$ & $18(16 \%)$ & $<5(<11 \%)$ \\
\hline CC & $8(5 \%)$ & $7(6 \%)$ & $<5(<11 \%)$ \\
\hline Inter-hospital transfer & $<5(<3 \%)$ & $<5(<5 \%)$ & $<5(<11 \%)$ \\
\hline Hospital ward & $51(33 \%)$ & $35(32 \%)$ & $16(36 \%)$ \\
\hline Home & $60(39 \%)$ & $39(36 \%)$ & $21(48 \%)$ \\
\hline Incomplete records & $7(5 \%)$ & $6(5 \%)$ & $1(2 \%)$ \\
\hline Total & 153 & 109 & 44 \\
\hline
\end{tabular}

Table 1 summarises demographic, patient dispersal, management and disposition information about major incident patients presenting to their original ED. Duplications resulting from any subsequent secondary inter-hospital transfer have been corrected for in these data. Primary receiving hospitals included MTC, a P-MTC, TU and LEH across GM and elsewhere in the UK. A Major Trauma Centre is the UK equivalent of a level-1 Trauma Centre in North America; a Trauma Unit is the equivalent of level-2 and a Local Emergency Hospital is level-3. Patient numbers requiring CC at each centre are indicated. Injury severity is summarised using the ISS and the NISS. Major injury by body region is summarised using the AIS. Population data include counts, percentages, medians and IQR as appropriate. Medians and IQR for systolic blood pressure, respiratory rate and Glasgow Coma Score on arrival in the ED are not presented due to the large amount of missing data (see figure 1).

AIS, Abbreviated Injury Severity Score; GM, Greater Manchester; ISS, Injury Severity Score; LEH, local emergency hospitals; MTC, major trauma centres; NISS, new ISS; P-MTC, paediatric MTC; TU, trauma units.

department of their choice (which was anticipated) including 14 patients presenting outside of the GMMTSN (table 1).

By 3:00 hour the following day, all ambulance transfers from incident scene had arrived at hospital-although patients selfpresented to hospitals both before and after this time, some with significant injuries (table 1). At 5.25 hour, NWAS declared the end of the major incident 'reception phase' while the more prolonged hospital 'definitive care phase' was unfolding. Following arrival in emergency departments, it proved impossible to retrieve patient-level data recorded at scene and so these data were not recorded in the TARN registry or linked to subsequent hospital care records.

\section{Information from hospitals}

The healthcare system treated 153 injured patients (109 adults and 44 paediatric patients) who attended emergency departments, including three hospital fatalities. As seen in table 1, a notable feature of these data is the age and sex profiles of patients, which can be explained by the presence of the young, predominately female, concert audience attracted by performer and the location and timing of the explosion in the entrance foyer where parents were waiting at the end of the concert. ${ }^{10}$ The majority of GMMTSN hospitals treated patients with injuries, with MTCs more likely to receive patients with major injuries and with a requirement for critical care when compared with trauma units and local emergency hospitals together (table 1 ). Indeed, 19 of a total of 24 critical care admissions were for patients attending MTCs. There were a small number (two children and three adults) who required subsequent secondary interhospital transfer in the first 24 hours, predominantly between MTCs for additional specialist definitive surgical care.
Figure 2 shows the number of patients each hour; (1) arriving in emergency departments; (2) undergoing surgical procedures in operating departments and (3) present in critical care units over the first 24 hours, displaying the movement of injured patients to hospital services as the incident relocates from scene to emergency departments, operating departments and critical care units. It also shows the lag phases for patient presentations to these services.

The number of patients in operating departments shows two peaks. The first was during the night when 21 patients received emergency life-saving damage control surgery direct from the emergency department (table 1). A second larger peak in operation departments use occurred the following day. The number of patients admitted to critical care units increased rapidly both during the night and the following afternoon, reflecting the pattern of surgical activity.

As noted above, there was an unusually large number of injured children involved in this incident and the regional paediatric MTC received $12 \%$ of its annual major trauma caseload in one night. Children and adults had similar proportions of injuries by injury severity grouping (table 1). The bomb blast, in combination with high-energy shrapnel penetration, predominantly resulted in limb and/or torso major life-threatening injuries in both children and adults (table 1), although a greater proportion of the major injuries in children were of head and chest compared with adults. The proportions of children and adults conveyed by NWAS ambulance from incident scene to hospital emergency departments were similar (table 1). The majority of children and adult patients arrived at emergency departments within the first 6 hours following bomb detonation (figure 2, table 1). However, for both children and adults, patients with 


\section{A New patients presenting to emergency departments}
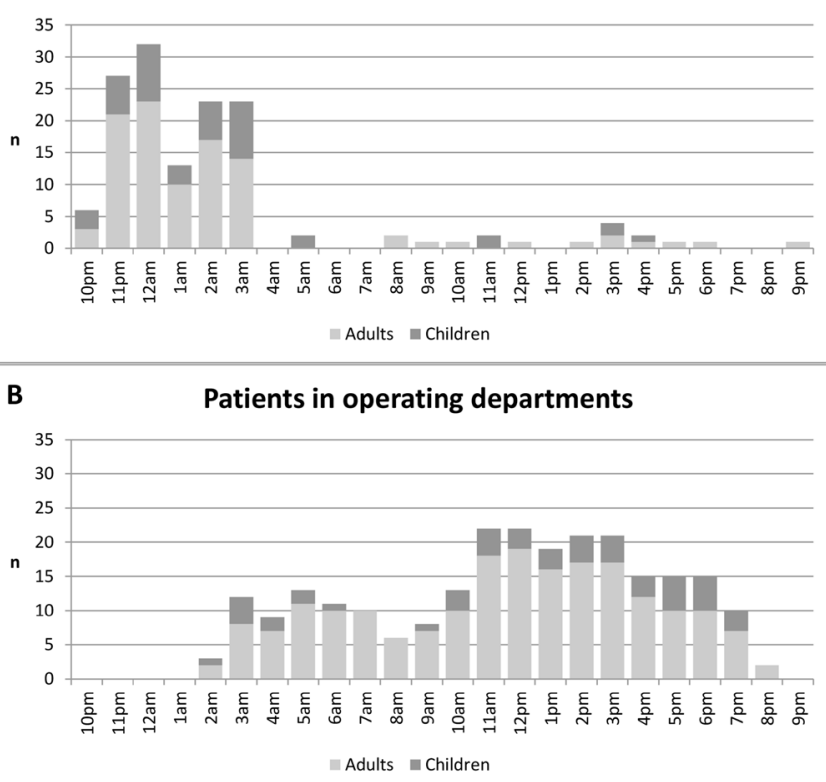

C

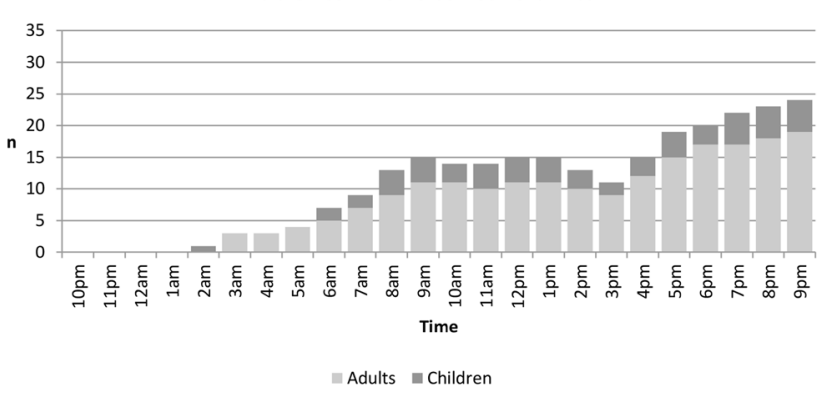

Figure 2 Incident patients per hour arriving at emergency departments (A), present in operating rooms (B) and critical care units (C) in first 24 hours. Patient numbers are shown per hour with the time axis indicting the start of each hour period.

either the most severe injuries (ISS $>15$ ) or the least severe injuries (ISS 1-8) were likely to arrive at a hospital emergency department in advance of those with intermediate severe injuries
(ISS 8-15) (table 1). In the first 6 hours, children and adults arriving by ambulance from incident scene had the most severe injuries (median ISS 14 (IQR 4-20) and 10 (6-14), respectively). In addition, children and adults arriving at emergency departments independent from planned emergency responses had the least severe injuries (median ISS 1(IQR 1-1) and 1 (IQR 1-1), respectively).

In emergency departments, computer tomography scans were performed for similar proportions of children and adults, and the times to first scan were similar for both groups (table 1). Similar proportions of children and adults required blood transfusion in the first 24 hours from bomb blast, with smaller volume used in children (table 1). Compared with adults, children were less likely to require emergency surgery and critical care direct from the emergency department and, overall, children were more likely to be discharged into the community following emergency department assessment and care (table 1).

Surgical operations for both children and adults (table 2) were most commonly performed on skin, soft-tissue and limbs-which was similar for emergency surgery over the night of the incident ('first wave'), emergent surgery the following day ('second wave') and repeated surgical interventions beyond the first 24 hours. Up to 30 days, the median number of surgical operations for both adults and children was 2 (IQR 1-3), and 3 (IQR 1-4) for patients managed at MTCs. Data presented in online supplemental figure S3 shows evidence for a long 'surgical tail' where patients required repeated surgery; most commonly for complex shrapnel, bone and soft tissue injuries of lower limbs.

Overall, surgical operations were most likely performed by senior trained surgeons (table 3) and, for the patients with the most severe injuries, were more likely provided by specialists at an MTC (table 1). For patients arriving at hospital, three patients died in an emergency department (table 1 ) and all those requiring hospital admission were alive at day 30 with their disposition summarised in online supplemental table $\mathrm{S} 1$.

\section{Information from Greater Manchester acute healthcare system}

Healthcare activity data on 22 May 2017, suggested an under pressure NHS acute hospital system across Greater Manchester prior to the incident (figure 3 and online supplemental figures S4-S9). Planned surgery was reduced markedly following the incident, recovering to usual patterns in the next week (figure 3).

Table 2 Surgical operations

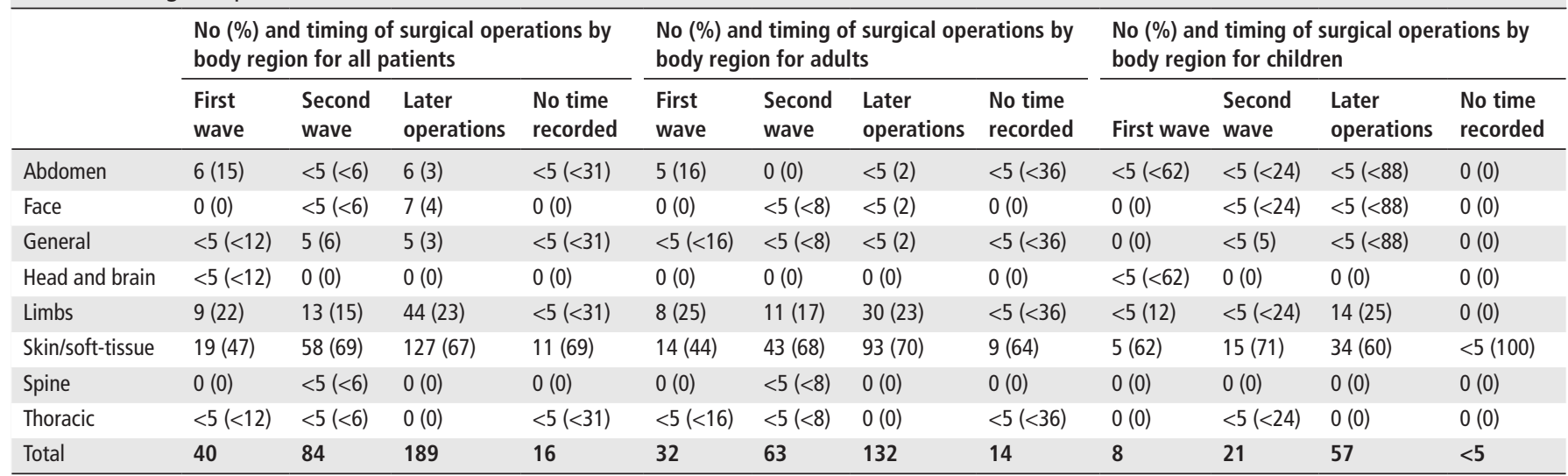

Table 2 shows the number (\%) of surgical operations performed by recorded body region for all patients and for adults and children alone. Timing of operations are split into 'first wave' (emergency surgery performed up to 9:00 hour on 23 May 2017), 'second wave' (emergent surgery performed after 9:00 hour on 23 May 2017) and 'later operations' (surgery performed after the first day up to 30 days following the incident). 

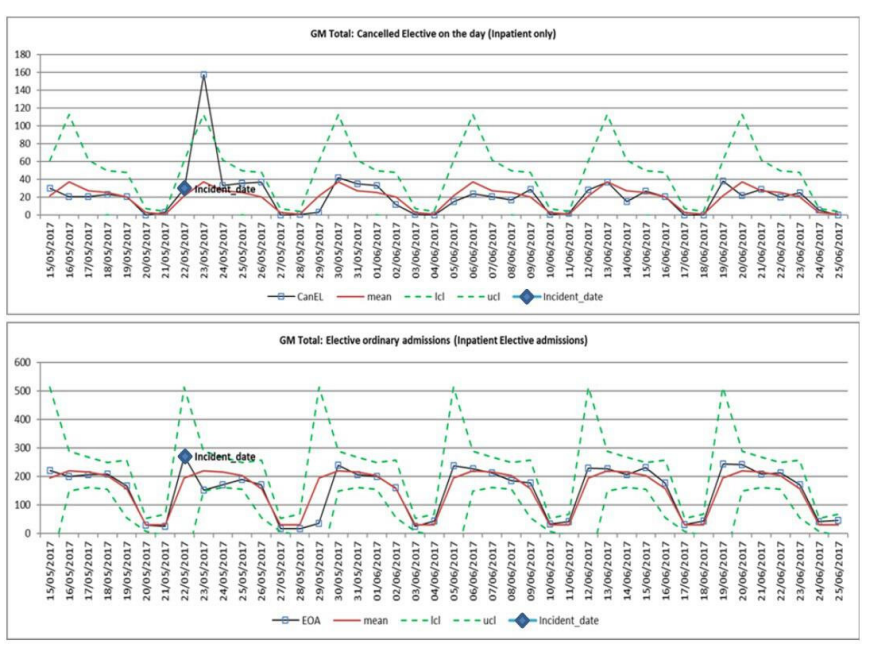

Figure 3 Shewhart (process behaviour) charts for both total daily elective surgical cancellations for patients already hospitalised and total daily hospital admission for elective surgery across Greater Manchester. Charts show patient (adult and children) data over six consecutive weeks for NHS hospitals across Greater Manchester (GM). Data for both the daily total elective surgical cancellations for patients already in hospital (CanEL) and the daily total hosptial admissions for elective surgery (EOA) are displayed. Mean data (red lines) are modelled for 3 months around the incident data (April-June 2017), with lower confidence limits ( $\mathrm{lcl}$ ) and upper confidence limits (ucl) indicating the $99.7 \%$ expected data limits. Actual recorded daily data are superimposed on these charts and the incident date (Monday 22nd May 2017) is marked. Note that Monday 29 May 2017 was a national holiday in England.

In addition, there was an immediate surge in hospital patient discharges into the community (online supplemental figure S6). There was also evidence of decreased emergency department visits for a number of weeks (online supplemental figure S4). There were sustained system-wide hospital service improvements with emergency departments increasing the proportion of patients treated within 4 hours (online supplemental figure S9), reductions in delays to transfer care into the community (online supplemental figure S7) and improvements in hospital bed utilisation (online supplemental figure S8).

\section{DISCUSSION}

We have shown that during the responses to a civilian major trauma terrorist incident, detailed patient-level information and routine hospital performance data can be collated and used to examine the demands placed on a city's healthcare system. To our knowledge, no similar data of this granularity have been presented previously either from terrorist incidents ${ }^{56}$ or humanitarian disasters. $^{18}$

A number of important lessons have been identified. The pattern of arrival of injured patients at emergency departments is important, reflecting the constraints at incident scene and providing an opportunity to implement hospital major incident plans to enhance emergency capacity. In a recent independent review, ${ }^{15}$ the factors that may have contributed to phasing of patients clearing the scene have been considered and systems learning recommended. The review also alluded to the importance of successful implementation of the Patient Dispersal Framework. At incident scene patients were evacuated, based on clinical priority, to a variety of hospitals with agreed predefined care capacity and clinical expertise best suited to a patient's needs. We believe that data presented here are consistent with successful implementation of this plan to enable an already under pressure regional hospital healthcare system to maintain resilience at a time of increased demand and provide the best available care to the patients it serves. For example, more severely injured adults and children were likely to be conveyed to hospital emergency departments by ambulance and these receiving hospitals were likely to be MTCs suggesting that incident scene triage was performed effectively. For this incident, effective implementation of the Patient Dispersal Framework at incident scene appeared particularly important to assure timely access to very specialised services such as paediatric trauma care-an important point previously identified by Carli et al following responses to terrorist events in France. ${ }^{19}$

We have documented the patterns of patient movement and subsequent care, spreading from incident scene into hospitals, and the consequent impact on 'normal' healthcare provision for both emergency and elective care. Our ability to provide emergency hospital care for both children and adults was never overwhelmed but was at the expense of a significant loss of planned surgical capacity and a reliance on local community services to help free up hospital capacity. Based on evidence presented here, we would recommend enhancing mutual aid planning with adjoining regions to improve both emergency and elective care capacity in the event of future potentially more complex incidents such as that encountered in Paris in 2015. ${ }^{11} 12$ Ideally, this would be an integrated national plan.

There are limitations to this report. Our major incident plans did not include provision for real-time capture of patient data. However, detailed patient information was captured from hospital records following a rapid decision to deploy the TARN registry. These data were near-complete except for high levels of missing recorded values for emergency department vital signs which resulted in a lack of reliable evidence

Table 3 Seniority of surgeon

\begin{tabular}{|c|c|c|c|c|c|c|c|c|c|c|c|c|}
\hline & \multicolumn{4}{|c|}{$\begin{array}{l}\text { No (\%) and timing of surgical operations by } \\
\text { surgeon seniority for all patients }\end{array}$} & \multicolumn{4}{|c|}{$\begin{array}{l}\text { No }(\%) \text { and timing of surgical operations by } \\
\text { surgeon seniority for adults }\end{array}$} & \multicolumn{4}{|c|}{$\begin{array}{l}\text { No }(\%) \text { and timing of surgical operations } \\
\text { by surgeon seniority for children }\end{array}$} \\
\hline & First wave & $\begin{array}{l}\text { Second } \\
\text { wave }\end{array}$ & $\begin{array}{l}\text { Later } \\
\text { operations }\end{array}$ & $\begin{array}{l}\text { No time } \\
\text { recorded }\end{array}$ & $\begin{array}{l}\text { First } \\
\text { wave }\end{array}$ & $\begin{array}{l}\text { Second } \\
\text { wave }\end{array}$ & $\begin{array}{l}\text { Later } \\
\text { operations }\end{array}$ & $\begin{array}{l}\text { No time } \\
\text { recorded }\end{array}$ & $\begin{array}{l}\text { First } \\
\text { wave }\end{array}$ & $\begin{array}{l}\text { Second } \\
\text { wave }\end{array}$ & $\begin{array}{l}\text { Later } \\
\text { operations }\end{array}$ & $\begin{array}{l}\text { No time } \\
\text { recorded }\end{array}$ \\
\hline Consultant & $36(90)$ & $75(90)$ & $158(84)$ & $15(94)$ & $31(97)$ & $56(89)$ & $104(79)$ & $14(100)$ & $5(62)$ & $19(90)$ & $54(95)$ & $1(50)$ \\
\hline Not consultant & $3(8)$ & $7(8)$ & $21(11)$ & $0(0)$ & $0(0)$ & $6(9)$ & $18(14)$ & $0(0)$ & $2(25)$ & $1(5)$ & $3(5)$ & $0(0)$ \\
\hline Not recorded & $1(2)$ & $2(2)$ & $10(5)$ & $1(6)$ & $1(3)$ & $1(2)$ & $10(8)$ & 0 & $1(12)$ & $1(5)$ & $0(0)$ & $1(50)$ \\
\hline
\end{tabular}

Table 3 shows the number (\%) of surgical operations performed by surgeon seniority for all patients and for adults and children alone. Timing of operations are split into 'first wave' (emergency surgery performed up to 9:00 hour on 23 May 2017), 'second wave' (emergent surgery performed after 9:00 hour on 23 May 2017) and 'later operations' (surgery performed after the first day up to 30 days following the incident). 
to allow a robust review of patient priority (triage) categories. High-quality data arising in the first few days, particularly on patterns of physical injury, did allow NHS England to anticipate impacts on regional healthcare provision; national supply chains; and the need to deploy national resources including public health services. ${ }^{20}$ NHS England were able to do this at an earlier stage than had been anticipated and these lessons on early patient data capture/collation have been incorporated into future national plans.

At an individual patient level, it was not possible for the TARN national registry to capture care data records from scene and to link these with records of subsequent hospital care, which we believe is a challenge internationally. A folding cruciform triage card information system deployed at scene for each patient did not prove robust enough to convey information into hospital care. In our view, major incident planning could be improved by developing individual patient identifiers, and an agreed core dataset, incorporating linked records from scene to hospital. Incident reporting templates have been proposed by other authors, but they lack the detail required to track patients through the system, typically either focusing on injury patterns ${ }^{21}$ or EMS systems. ${ }^{522}$ Innovations to facilitate patient information collection and data presentation should be considered as part of planned system-wide responses. The development and provision of computerised tools to collect and visualise streaming data could be a further beneficial development.

The benefits of collecting standardised healthcare data have been recognised internationally. For example, there is an internationally established system for reporting data about cardiac arrest resuscitation in the community. ${ }^{23}$ While such emergencies are relatively rare in any one locality, they occur internationally with sufficient frequency that standardised data collection has generated a significant body of information. ${ }^{23}$ This has informed the preparation of protocols for the most effective emergency treatment. Suggestions for international data collection for hospital responses to major trauma events have been proposed since the $1990 s^{1262425}$ but have not been widely adopted. Recent civilian terrorist events are creating an urgent public health need to re-energise this work to develop data driven evidence to underpin system improvements. ${ }^{9}$ In England, as a direct response to our recommendations, the TARN registry has developed a major incident module for deployment at future major trauma incidents. The extension of this approach so that anonymised data are collected internationally, to an agreed standard, would significantly increase the volume of data available to researchers and emergency planners.

Finally, we were unable to identify robust data sources to report on patients with minor injuries who may have presented to, and received their care, at community family medicine facilities rather than emergency hospital departments. In addition, we do not know the true impact on community-based healthcare services of cancelled elective surgical operations, increased hospital discharges into community care and the sustained reductions in emergency department attendances in the weeks following the incident. However, the richness of the hospital data that we have gathered will permit separate deeper analysis such as modelling patient surge capacity as well as understanding impacts on imaging departments, blood transfusion and other hospital services. Additional work is progressing on data about longer term patient reported outcomes; responses to physical rehabilitation; and learning from population psychological screening, interventions and recovery.

\section{CONCLUSIONS}

The systematic collation of injured patient and healthcare system data has provided an objective evaluation of a regional major incident plan and provided insight into healthcare system resilience.

Major civilian trauma events are rare in any one country but are not an uncommon global event. The preplanned collection, archiving and use of patient and healthcare data in an agreed, standardised way would facilitate improvements in the evidence base and learning from future incidents internationally.

\section{Twitter Paul Dark @DarkNatter and Simon Carley @EMManchester}

Acknowledgements We thank Zoe Talks and Magdalena Karolczak-Bayatti, former research managers, Inflammation and Repair Domain, Manchester Academic Health Sciences Centre, UK. We also thank Jane Worthington, former Vice-Dean of the Faculty of Biology, Medicine and Health, University of Manchester, lan Sargeant, Defense Medical Services, Birmingham, Richard Preece, former Executive Lead for Quality and Caldicott Guardian for the Greater Manchester Health and Social Care Partnership, Andrea Dayson, former Associate Director, Greater Manchester Joint Commissioning Group, Ruth Bromley, Lead for Ethics and Law, University of Manchester Medical School, Detective Superintendent Teresa Lam, Family Liaison Lead, Operation Manteline, Greater Manchester Police and Lloyd Gregory, Academic Partnerships Director, Health Innovation Manchester, UK.

Collaborators Manchester Academic Health Science Centre (MAHSC) Collaborators:Paul Dark; Martin Smith; Harry Ziman; Simon Carley; Fiona Lecky; Naomi Davis; Jane Eddleston; Victoria Parr; Karren Berry; Michael Wafer; David Ratcliffe; Antoinette Edwards; Mike Young; Omar Bouamra; Tom Lawrence; Maydul Islam; Andrew Mullarkey; Seamus McGirr; Jason Wong; Adam Reid; Rachel Jenner; Anthony Gleeson; Matthew Davenport; Gordon Carlson; Stella Smith; Fiona Murphy; Daniel Holsgrove; Jill Windle; Alistair Rennie; Amer Shoaih; lan Kamaly-Asl; Timothy Coats; Christopher Moran; Keith Willett; Andrea Bartolucci; Anthony Redmond.

Contributors PD, MS, HZ, SC and FL were responsible for reviewing the literature, and were responsible for project design, data collection, data analysis, data interpretation, writing, and reviewing the report; they take overall responsibility for this report. Authors contributed equally to this manuscript.

Funding This study was supported by Manchester Academic Health Sciences Centre, Health Innovation Manchester.

Competing interests None declared.

Patient consent for publication Not required.

Provenance and peer review Not commissioned; externally peer reviewed.

Data availability statement All data relevant to the study are included in the article or uploaded as online supplemental information. Individual patient data are not available due to the sensitivity of the incident and the HRA ethical framework. Please contact the Trauma Audit and Research Network (TARN) registry by email ( support@tarn.ac.uk) for more details about the available Major Incident audit module.

Supplemental material This content has been supplied by the author(s). It has not been vetted by BMJ Publishing Group Limited (BMJ) and may not have been peer-reviewed. Any opinions or recommendations discussed are solely those of the author(s) and are not endorsed by BMJ. BMJ disclaims all liability and responsibility arising from any reliance placed on the content. Where the content includes any translated material, BMJ does not warrant the accuracy and reliability of the translations (including but not limited to local regulations, clinical guidelines, terminology, drug names and drug dosages), and is not responsible for any error and/or omissions arising from translation and adaptation or otherwise.

Open access This is an open access article distributed in accordance with the Creative Commons Attribution Non Commercial (CC BY-NC 4.0) license, which permits others to distribute, remix, adapt, build upon this work non-commercially, and license their derivative works on different terms, provided the original work is properly cited, appropriate credit is given, any changes made indicated, and the use is non-commercial. See: http://creativecommons.org/licenses/by-nc/4.0/.

\section{ORCID iDs}

Paul Dark http://orcid.org/0000-0003-3309-0164

Simon Carley http://orcid.org/0000-0003-1561-5553

Fiona Lecky http://orcid.org/0000-0001-6806-0921

\section{REFERENCES}

1 Mackway-Jones K, Carley S. An international expert Delphi study to determine research needs in major incident management. Prehosp Disaster Med 2012;27:351-8. 
2 Carley S, Mackway-Jones K, Donnan S. Major incidents in Britain over the past 28 years: the case for the centralised reporting of major incidents. J Epidemiol Community Health 1998;52:392-8.

3 Turner CDA, Lockey DJ, Rehn M. Pre-Hospital management of mass casualty civilian shootings: a systematic literature review. Crit Care 2016;20:362

4 Timbie JW, Ringel JS, Fox DS, et al. Systematic review of strategies to manage and allocate scarce resources during mass casualty events. Ann Emerg Med 2013;61:677-89.

5 Hardy SEJ, Fattah S. Trials and tribulations: how we established a major incident database. Scand J Trauma Resusc Emerg Med 2017;25:7.

6 Hardy S. Major incidents in England. BMJ 2015;350:h1712-2.

7 McElroy JA, Steinberg S, Keller J, et al. Operation continued care: a large mass-casualty, full-scale exercise as a test of regional preparedness. Surgery 2019;166:587-92.

8 Public Health England. Report on exercise Socrates: greater Manchester health system Emergo exercise; 2017 [Accessed 29 March 2017].

9 Goralnick E, Van Trimpont F, Carli P. Preparing for the next terrorism attack: lessons from Paris, Brussels, and Boston. JAMA Surg 2017;152:419-20.

10 Service Médical du RAID. Tactical emergency medicine: lessons from Paris marauding terrorist attack. Crit Care 2016;20:37.

11 Hirsch M, Carli P, Nizard R, et al. The medical response to multisite terrorist attacks in Paris. Lancet 2015;386:2535-8.

12 Raux M, Carli P, Lapostolle F, et al. Analysis of the medical response to November 2015 Paris terrorist attacks: resource utilization according to the cause of injury. Intensive Care Med 2019;45:1231-40.

13 Gates JD, Arabian S, Biddinger P, et al. The initial response to the Boston marathon bombing: lessons learned to prepare for the next disaster. Ann Surg 2014;260:960-6.

14 TRAUMABASE Group. Paris terrorist attack: early lessons from the intensivists. Crit Care 2016;20:88.

15 The Kerslake Review Panel. The Kerslake report: an independent review into the preparedness for, and emergency response to, the Manchester arena attack on 22nd may 2017, 2018. Available: https://www.kerslakearenareview.co.uk/media/1022/ kerslake_arena_review_printed_final.pdf

16 Lecky F. Twenty-Five years of the trauma audit and research network: a continuing evolution to drive improvement. Emerg Med J 2015;32:906-8.

17 Koutras MV, Bersimis S, Maravelakis PE. Statistical process control using Shewhart control charts with supplementary runs rules. Methodol Comput Appl Probab 2007;9:207-24.

18 Jafar AJN, Norton I, Lecky F, et al. A literature review of medical record keeping by foreign medical teams in sudden onset disasters. Prehosp Disaster Med 2015;30:216-22.

19 Carli P, Pons F, Levraut J, et al. The French emergency medical services after the Paris and NICE terrorist attacks: what have we learnt? Lancet 2017;390:2735-8.

20 Moran CG, Webb C, Brohi K, et al. Lessons in planning from mass casualty events in UK. BMJ 2017;359:j4765.

21 Carley SD, Mackway-Jones K. The casualty profile from the Manchester bombing 1996: a proposal for the construction and dissemination of casualty profiles from major incidents. J Accid Emerg Med 1997;14:76-80.

22 Fattah S, Rehn M, Lockey D, et al. A consensus based template for reporting of prehospital major incident medical management. Scand J Trauma Resusc Emerg Med 2014;22:5.

23 Jacobs I, Nadkarni V, Bahr J, et al. Cardiac arrest and cardiopulmonary resuscitation outcome reports: update and simplification of the Utstein templates for resuscitation registries: a statement for healthcare professionals from a task force of the International liaison Committee on resuscitation (American heart association, European resuscitation Council, Australian resuscitation Council, New Zealand resuscitation Council, heart and stroke Foundation of Canada, InterAmerican heart Foundation, resuscitation councils of southern Africa). Circulation 2004;110:3385-97.

24 Adini B, Peleg K. On constant alert: lessons to be learned from Israel's emergency response to mass-casualty terrorism incidents. Health Aff 2013;32:2179-85.

25 Tami G, Bruria A, Fabiana E, et al. An after-action review tool for EDs: learning from mass casualty incidents. Am J Emerg Med 2013;31:798-802. 